INTERNATIONAL HIGHER EDUCATION Number 75 Spring 2014

Pages 3-5

\title{
How Corruption Puts Higher Education at Risk
}

\section{STEPHEN P. HEYNEMAN}

Stephen P. Heyneman is professor of international education policy at Vanderbilt University, Nashville, Tennessee. E-mail: s.heyneman@vanderbilt.edu.

Competition for resources and fame place pressures on higher education institutions. Weaker institutions are more prone to corruption. In some instances, corruption has invaded university systems and threatens the reputation of research products and diplomas. Where this has occurred, corruption has reduced the individual and social economic rate of return on higher education investments. Some countries have acquired a reputation for academic dishonesty, raising questions about all graduates and doubts about all institutions.

Corruption can arise at the early stage of recruitment and admission. Students may feel they have to pay a shadow price, to be admitted to a particular university program. Some students pay bribes as an insurance policy, because they do not want to be left behind for not paying a bribe.

Financial fraud remains a major challenge. Reductions in public finance have affected systems of internal control to prevent fraud. Because each faculty may have separate cost centers, financial monitoring may be difficult. Nor is it 
easy to monitor student associations that handle money separately from the university administration.

Directly related to the global internet, access is an avalanche of so-called "degree mills" - thousands of them, located in all regions. There is a Wikipedia page that lists house pets that have earned degrees. How might one recognize a degree mill? They often promise a degree within a short amount of time and with low costs; they give credit for nonacademic experience; their Web sites often list their addresses as being a postbox. Equally, problematic are fake accreditation agencies, promising quick assessments and permanent accreditation.

Cross-border educational programs raise questions in three areas: the recognition of degrees, the use of recruitment agents to encourage international students, and the establishment of programs abroad by institutions of dubious reputation. Though cross-border provision raises new risks of corruption, it may also be a conduit for cross-border integrity. Cross-border provision of excellence in higher education can offer a rare opportunity for local students and institutions to observe how a corrupt-free institution operates.

To attract students, institutions may exaggerate the success of their graduates. This may be a particular problem with the for-profit institutions and with particular low-quality programs in the vocations. Academic integrity consists of honesty, trust, respect, fairness, and responsibility and is fundamental to the reputation of academic institutions. A lack of integrity includes the practice of plagiarism, cheating, unauthorized use of others' work, paying for assignments claimed as one's own, the falsification of data, downloading 
assignments from the internet, the misrepresentation of records, and fraudulent publishing. It also includes paying for grades with gifts, money, or sexual favors.

\section{Areas Needing Careful Discussion}

Definitional limits. When universities are not managed well, some suggest that it is a sign of corruption. Inefficiency, a concentration of power, slowness in making decisions, and a reluctance to share confidential information are not signs of corruption. When educational institutions seek nontraditional sources of income, some may confuse that with corruption-although wherever legal, it is not.

Differences in corruption levels. There are instances of corruption in every country, but this does not mean that corruption is distributed identically. In some circumstances it is endemic, affecting the entire system; in other cases it is occasional. In some circumstances it is monetary in nature; in others it tends to center on professional transgressions, such as plagiarism. Where international students intend to study is relevant. In general, students act to leave places where corruption is rampant and prefer to study where it is minor.

Differences between institutional and individual corruption. Causes and solutions need to be differentiated. Institutional corruption-financial fraud, the illegal procurement of goods and services, and tax avoidance-are problems that can be handled through the enforcement of legislation. Individual corruptionincluding faculty misbehavior, cheating on examinations, plagiarism, the falsification of research results-constitutes transgressions of codes of professional conduct. In the first, the main control is through legislation and 
enforcement in court. In the second, control is internal to the university. Legislation should not attempt to include infractions of individual corruption, on behalf of individual students and faculty.

\section{THE ENVIRONMENT AND CORRUPTION}

Though competition for revenues places pressures on faculty, it is insufficient to use such pressures as an excuse to engage in corrupt practices. Nor, is it sufficient to suggest that, because corrupt behavior is common, one's own participation can be excused. Even in environments in which corruption is virtually universal there are "resisters" to corruption.

\section{Are Anticorruption Measures International?}

Some individuals suggest that anticorruption measures should be based on domestic values and laws. Although numerous instances seem correct, there appear to be some instances in which universal measures are already the norm. For instance, in the case of universities ranked by the Times Higher Education magazine across 40 countries, 98 percent ethical infrastructure elements-on their Web sites-codes of conduct for faculty, students, and administrators, honors councils.

\section{FUTURE WORK}

International agencies have an important role. Finding ways to combat higher education corruption is a viable candidate for the United Nations Educational, Scientific, and Cultural Organization's attention and extrabudgetary support. 
UNESCO could assist countries to establish strategies covering examination procedures, accountability and transparency codes, and adjudication structures, such as student and faculty courts of conduct.

The Council of Europe and the European Union have important roles. To participate in the Bologna process, universities and the countries seek to be recognized. The recognition procedure could include mechanisms to combat corruption. Development assistance agencies also have important roles. Among criteria for project, approval might be the corruption infrastructure noted above. In addition, countries might be held accountable for their anticorruption performance, based on the evidence that corruption had declined, that the level of transparency had increased, and that the public perception of corruption had shifted downward.

In regular surveys, Transparency International has assisted the understanding of general corruption by gauging the degree to which a nation's business and government are believed to be corrupt. A similar set of indicators could be used on higher education. It could be a matter of pride, to find that the level of participation and the public perception of corruption are on the decline. If governments encourage such surveys, it is a healthy sign; if governments forbid such surveys, it is a sign that they have not yet understood the level of risk involved by being passive.

Perception is all-important. It is common to deny wrongdoing. "Where is the evidence?" one might ask. This is the wrong approach. When an institution is perceived to be corrupt, the damage is already done. Perception is the only evidence needed for harmful effects to occur. This is one reason why all worldclass universities post anticorruption efforts on their Web sites. This implies that 
any university, in any culture, that has ambitions to become world class is required to erect a similar ethical infrastructure. This may require a change of attitude on the part of many rectors and university administrators. It may require them to shift from a mode of self-protection and denial to a mode of transparency and active engagement, even when the evidence may be disturbing and/or painful. If the best universities in the world submit themselves to such ethical inspections, then the others can too. 